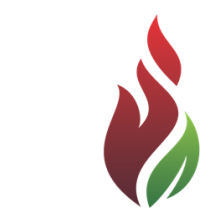

SUSTENERE

Publishing Corporation

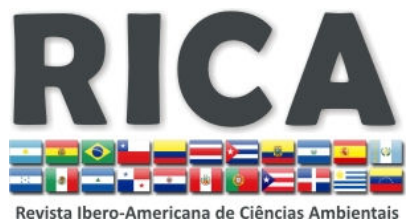

Journals Homepage:

www.sustenere.co/journals

\section{COMPOSIÇÃO GRAVIMÉTRICA DOS RESÍDUOS \\ SÓLIDOS DESTINADOS PARA UMA CENTRAL DE TRIAGEM, COMPOSTAGEM E DISPOSIÇÃO FINAL}

\section{RESUMO}

A geração de resíduos sólidos domésticos tem intensificado devido aos novos hábitos de consumo e ao aumento populacional, dessa forma a preocupação com o gerenciamento dos mesmos tem crescido. Nesse sentido, a caracterização gravimétrica, surge como uma importante ferramenta, pois, demostra os tipos e quantidades de resíduos coletados, valorando-os em porcentagem com relação a sua massa. O estudo caracterizou os resíduos de um grupo de 30 municípios, abrangendo cerca de 95.000 habitantes. Constatou-se que a matéria orgânica correspondia a $60,3 \%$ em peso do total de resíduos destinados a central de triagem, compostagem e disposição final, $18,2 \%$ destes resíduos eram materiais recicláveis e $21,5 \%$ rejeitos. Através do estudo, verificou-se que do total de resíduos sólidos domésticos coletados, aproximadamente $80 \%$ em peso eram passíveis de reaproveitamento.

PALAVRAS-CHAVES: Resíduos Sólidos Domésticos; Caracterização Gravimétrica; Triagem; Compostagem; Destinação Final.

\section{GRAVIMETRIC COMPOSITION OF SOLID WASTE INTENDED FOR CENTRAL OF SCREENING, COMPOSTING AND FINAL DISPOSAL}

\section{ABSTRACT}

The generation of domestic waste has intensified due to new consumer habits and population increase, thus the concern with managing them has grown. In this sense, the characterization gravimetric emerges as an important tool because, demonstrates the types and quantities of waste collected, valuing them as a percentage in relation to its mass. The study characterized the waste of a group of 30 municipalities, covering about 95.000 habitants. It was found that the organic matter amounted to $60,3 \%$ by weight of total waste for central of screening, composting and disposal, $18,2 \%$ of these waste materials were recycled and $21,5 \%$ tailings. Through the study, it was found that the total domestic waste collected, about $80 \%$ by weight were capable of reuse.

KEYWORDS: Domestic Solid Waste; Characterization Gravimetric; Screening; Composting; Disposal.
Revista Ibero-Americana de

Ciências Ambientais, Aquidabã, v.5, n.1, Dez 2013, Jan, Fev, Mar, Abr, Mai 2014.

ISSN 2179-6858

\section{SECTION: Articles}

TOPIC: Saneamento e Tratamento de Resíduos

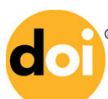

DOI: 10.6008/SPC2179-6858.2014.001.0020

Odorico Konrad

Centro Universitário Univates, Brasil http://lattes.cnpq.br/9946679953072196

okonrad@univates.br

Thanabi Bellenzier Calderan

Centro Universitário Univates, Brasil http://lattes.cnpq.br/3488551373348091

thanabi@net11.com.br

Nara Paula Schmeier

Centro Universitário Univates, Brasil http://lattes.cnpq.br/3097972725462326

naraschmeier@gmail.com

Camila Elis Casaril

Centro Universitário Univates, Brasil http://lattes.cnpq.br/1321651292592048

ccasaril@universo.univates.br

Marluce Lumi

Centro Universitário Univates, Brasil marlucelumi@gmail.com

Received: 03/09/2013

Approved: 10/04/2014

Reviewed anonymously in the process of blind peer.

\section{Referencing this:}

KONRAD, O.; CALDERAN, T. B.; SCHMEIER, N. P.; CASARIL, C. E.; LUMI, M.. Composição gravimétrica dos resíduos sólidos destinados para uma central de triagem, compostagem e disposição final. Revista Ibero-Americana de Ciências Ambientais, Aquidabã, v.5, n.1, p.284-292, 2014. DOI: http://dx.doi.org/10.6008/SPC21796858.2014 .001 .0020 


\section{INTRODUÇÃO}

Dentre os assuntos da temática ambiental, a questão dos resíduos sólidos urbanos é sempre um dos temas que se destaca em decorrência da geração dos mesmos estar crescendo com o rápido aumento da população e à medida que se modificam os hábitos de consumo. Além disso, existe uma grande preocupação por parte dos municípios em adequar-se a Política Nacional de Resíduos Sólidos (PNRS).

Em 2008, o Instituto Brasileiro de Geografia e Estatística (IBGE, 2010) atualizou dados relativos à situação do saneamento no país, quando detectou que todos os municípios brasileiros tinham manejo dos resíduos sólidos (que inclui coleta e destinação final dos resíduos e limpeza pública). No quesito coleta seletiva, o Brasil tem evoluído segundo IBGE (2010), em 1989 apenas 58 municípios brasileiros tinham coleta seletiva, no ano de 2000 já eram 451 municípios e em 2008, o Brasil atingiu a marca de 994 cidades atendidas pela coleta seletiva (o Brasil possuía em 2008, 5.564 municípios). A PNRS incentiva a implementação da coleta seletiva, através da priorização da sessão de recursos da União para municípios que implantarem a coleta seletiva integrando o trabalho de catadores e cooperativas na triagem dos materiais recicláveis (BRASIL, 2010).

No Rio Grande do Sul em meados do ano de 2008, dos 496 municípios, 450 possuíam o serviço de coleta regular de resíduos sólidos nas vias e logradouros públicos, do centro e dos bairros. Do total de municípios gaúchos, em 166 havia serviço de coleta seletiva. Destes, em 78 a coleta seletiva acontecia em todo município, em 73 só na área urbana e em 14, apenas em alguns bairros (IBGE, 2010). De acordo com Braga et al. (2008), a quantidade de resíduos sólidos gerada nos domicílios está relacionada a fatores como dia da semana e do mês, condições climáticas, datas comemorativas, desempenho da economia, o poder de compra da população e aspectos socioeconômicos e culturais que afetem a forma de consumo de uma dada população.

Bidone e Povinelli (1999) citam ainda a influência do sexo e da idade dos grupos populacionais na geração dos resíduos. Para estes autores, a geração de resíduos está vinculada com as atividades básicas do ser humano para a manutenção da vida. Porém, mesmo que a geração de resíduos esteja ligada as necessidades básicas do ser humano para a sobrevivência, frequentemente deparamo-nos com excessos como o de embalagens e a obsolescência programada dos produtos adquiridos, o que contribui para um aumento ainda maior da geração de resíduos. Segundo Tabalipa e Fiori (2006), a forma de consumo e a produção de bens e serviços atual, tem gerado uma grande quantidade de subprodutos e resíduos, que podem implicar em problemas tanto econômicos quanto ambientais, dependendo das suas características e quantidades geradas.

O aumento na geração de resíduos faz com que as administrações, das esferas municipal, estadual e nacional, tenham que se focar com maior atenção na questão do gerenciamento dos resíduos sólidos. Oliveira (1998) e a PNRS (BRASIL, 2010) neste sentido, afirmam que todos os 
cidadãos têm seu papel na solução dos problemas relacionados ao gerenciamento de resíduos, no entanto as administrações públicas tem poder para decidir como este será realizado. Segundo o referido autor e a PNRS, para que o sistema de gerenciamento seja bem sucedido, será necessário contar com auxílio externo à administração local, no caso, os governos federal e estadual, além da participação e envolvimento da comunidade local e do setor privado. Para Calderan e Konrad (2011), o governo nacional precisa compreender que a municipalidade e o estado não possuem recursos financeiros suficientes para o gerenciamento dos resíduos, sendo necessário o apoio com subsídios do governo federal e do setor privado.

Calderan e Konrad (2011) afirmam ainda, que a grande contribuição da PNRS será justamente compartilhar a responsabilidade ambiental dos resíduos com toda a cadeia de consumo. $\mathrm{O}$ cidadão tem a responsabilidade de consumir de forma ambientalmente consciente e quitar seus impostos, já o poder público deverá garantir a prestação de serviços quanto ao tratamento dos resíduos sólidos de maneira eficiente e ambientalmente segura.

Para Bidone e Povinelli (1999), a solução do problema quanto à geração excessiva de resíduos também está em um gerenciamento com foco na redução de geração, reutilização e reciclagem, práticas que devem ser apoiadas em princípios de educação ambiental da população tendo em vista que, é o consumidor que tem a decisão de dizer não aos hábitos consumistas e insustentáveis. O poder público deve incentivar a população a reduzir os resíduos gerados, reordenando hábitos do dia-a-dia e combatendo o desperdício, além de incentivar a reciclagem quando não há mais como reduzir ou reutilizar os resíduos gerados (LIMA, 2001).

A separação dos materiais recicláveis cumpre um papel estratégico na gestão integrada de resíduos sólidos em vários aspectos: estimula o hábito da separação do resíduo na fonte geradora para o seu aproveitamento, promove a educação ambiental voltada para a redução do consumo e do desperdício, gera trabalho e renda e melhora a qualidade da matéria orgânica para a compostagem, Além disso, garante uma maior vida útil para as células dos aterros sanitários, propicia a disposição ambientalmente adequada dos resíduos, favorecendo a proteção do solo, água e ar, e, principalmente, contribui para a execução correta do gerenciamento dos resíduos sólidos (TABALIPA \& FIORI, 2006).

Outra ferramenta importante para que se possa realizar uma gestão dos resíduos domésticos de forma correta e ambientalmente segura, é a analise da composição gravimétrica ou caracterização quanti-qualitativa (PESSIN et al., 2006). Constitui-se na determinação dos tipos e quantidades de resíduos, valorados em porcentagem com relação a sua massa. A importância desse tipo de estudo, está em acompanhar a realidade local com relação aos resíduos gerados, servindo estes dados de base para os planos de gerenciamento dos resíduos sólidos urbanos e domésticos.

Segundo Castilhos Júnior (2003), a quantidade exata de resíduos gerados é de difícil determinação pelo fato da mesma sofrer interferência pelo armazenamento, reutilização, reciclagem e descarte em ambientes inadequados, o que acaba por desviar partes dos materiais 
antes da destinação final. Essas interferências fazem com que se determine apenas, a quantidade de resíduos sólidos coletados. No entanto, são diversas as metodologias utilizadas na caracterização dos resíduos, tendo vista os diferentes objetivos desta.

De acordo com Pessin et al. (2006), independente da metodologia utilizada e dos objetivos que se tem em vista, alguns itens devem ser levados em conta ao se construir uma análise de dados sobre os resíduos sólidos gerados em um determinado local. Deve-se estar atento, por exemplo, a amostragem de resíduos a ser estudada, ao comportamento da população com o manejo dos resíduos, a condição econômica e de coleta, é preciso também realizar caracterizações periódicas, a fim de traçar um histórico da evolução da geração e destinação de resíduos nos municípios. Dessa forma, será possível formular as diretrizes da gestão dos resíduos domésticos com mais segurança, pois, se terá a consciência de quais resíduos são gerados em maior quantidade e quais requerem maior atenção quanto ao gerenciamento.

Costa et al. (2012) realizaram caracterização gravimétrica dos resíduos sólidos domésticos de uma população urbana de 28.310 habitantes, averiguando que $46,45 \%$ dos resíduos em massa com relação a massa total dos resíduos avaliados correspondia a matéria orgânica, 13,43\% a plástico, $12,48 \%$ papel/papelão, $4,26 \%$ metal, $3,32 \%$ vidro e que $19,7 \%$ dos resíduos correspondiam a outros materiais como borracha, têxteis, madeira, material higiênico e de difícil identificação. Na soma dos percentuais percebe-se que $80,3 \%$ dos materiais caracterizados tinham potencial para serem reaproveitados, seja por compostagem $(46,45 \%)$ ou por reciclagem $(33,85 \%)$.

Cabe ressaltar, que ainda que o tratamento dos resíduos seja de reponsabilidade de cada município, sabe-se que os problemas decorrentes da má disposição dos mesmos não se limitam as fronteiras de uma cidade. Além do mais, a reversão do atual padrão de desenvolvimento, em direção à sustentabilidade ambiental, tem no manejo adequado dos resíduos sólidos, um de seus maiores desafios. A adoção das práticas de gerenciamento integrado pelas municipalidades poderia ser a base do processo de enfrentamento do problema. Nesse sentido, os consórcios intermunicipais de coleta e destinação dos resíduos sólidos domésticos são um sistema em ascensão, pois englobam interesses comuns de seus integrantes e permitem não só o planejamento local, mas também o regional. Estes consórcios abrangem principalmente pequenos e médios municípios. (JACOBI, 2006).

A implantação de consórcios intermunicipais é um empreendimento vantajoso para os pequenos e médios municípios, pois há uma tendência à falta de recursos financeiros e técnicos por parte destes. Estas cidades, não tem capacidade para instalar e manter aterros sanitários que estejam dentro dos padrões exigidos pela legislação vigente. Nesse âmbito, os consórcios são uma alternativa para que as administrações locais realizem de fato um gerenciamento adequado dos resíduos sólidos domésticos (CALDERAN, 2013). Diante da revisão exposta, o presente estudo objetiva apresentar a composição gravimétrica dos resíduos sólidos destinados para uma central de triagem, compostagem e destinação final, gerenciada por um consórcio intermunicipal. 


\section{METODOLOGIA}

O objeto de estudo desse artigo é um consórcio do interior do Estado do Rio Grande do Sul, que abrange 30 municípios, cujas populações atendidas com a coleta de resíduos sólidos domésticos totalizam aproximadamente 95.000 habitantes. Grande parte dos municípios avaliados é de pequeno porte $(56,6 \%)$, com até 3.000 habitantes, $30 \%$ dos municípios estudados possuem população entre 5.000 a 10.000 habitantes e 13,4\% tem população superior a 10.000 habitantes.

O grupo consorciado mantém uma central de triagem, compostagem e destinação final de resíduos, no entanto, a coleta e transporte dos resíduos gerados até a central é de responsabilidade das administrações públicas. Em alguns casos o serviço é efetuado pelo próprio município, enquanto que em outros é realizado por empresas terceirizadas.

Para diagnosticar a situação dos resíduos sólidos gerados, foram realizadas análises qualitativas e quantitativas dos materiais destinados a central de triagem, compostagem e destinação final de resíduos no ano de 2011, pois segundo Zanim e Mancini (2004), tão importante quanto à qualidade dos materiais (tipos de material) presentes nos resíduos é a quantidade dos mesmos (porcentagem em massa). As análises consistiram em observações do funcionamento do processo de triagem e tratamento e disposição dos resíduos.

Para a determinação da quantidade de resíduos gerenciados pelo consórcio e respectiva caracterização física, acompanhou-se a pesagem das parcelas destinadas ao aterro sanitário, ao pátio de compostagem e os resíduos triados com potencialidade à reciclagem. A pesagem do resíduo era realizada em uma balança, no momento em que o mesmo chegava à central de triagem, ainda no caminhão coletor, e após as etapas de segregação realizadas na esteira da central de triagem, onde se identificou a quantidade de resíduos destinados para o pátio de compostagem, reciclagem e o rejeito destinado para o aterro sanitário.

A segregação ocorria nos seguintes grupos: matéria orgânica, material reciclável e rejeito. A matéria orgânica inferiu toda fração passível de compostagem (resíduos alimentares, folhas secas, madeiras, aglomerados, restos de jardinagem...), além de restos de madeira e aglomerados. O material reciclável inferiu vidro, metal, plástico, papel, papelão e tetrapack e a fração considerada rejeito, tecidos, borracha, couro, fraldas, calçados, dentre outros.

Ao que tange os materiais encaminhados às indústrias de reciclagem, observou-se que a realização de triagem minuciosa dos mesmos. O material plástico era é separado por sua composição em: PET (Politereftalato de etileno), PP (Polipropileno), PEAD (Polietileno de Alta Densidade) e PEBD (Polietileno de baixa densidade). O material vidro, também passava por nova segregação: em vidro inteiro e vidro quebrado, de modo que os primeiros eram encaminhados diretamente para venda e os demais passavam por um processo de moagem antes da mesma. Outros materiais que também são separados, enfardados e vendidos são papel/papelão/tetrapack e metais. 


\section{RESULTADOS}

No acompanhamento das pesagens, durante o ano 2011, foi constatado que cerca de 1.150.000 Kg de resíduos foram coletados e destinados à central de triagem, compostagem e destinação final pelos municípios consorciados, equivalendo a uma geração per capita média de 0,44 Kg.hab ${ }^{-1} \cdot \mathrm{dia}^{-1}$. O valor constatado está em concordância com o de outros estudos que obtiveram média de geração per capita semelhante, como o trabalho de Konrad (2002), com geração média de $0,51 \mathrm{Kg} \cdot \mathrm{hab}^{1} \cdot \mathrm{dia}^{-1}$ para uma população de 28.098 habitantes e o de Franco (2012) que encontrou uma geração de $0,44 \mathrm{Kg}_{\text {hab }}$ hadia-1 $^{-1}$ para um grupo de 20 municípios de até 20.000 habitantes. Estudos em cidades de populações maiores, apontam uma tendência de geração per capita distinta, como se pôde avaliar nos trabalhos de Konrad, Casaril e Schmitz (2010) e Schneider et al. (2002) que analisaram um municípios com população de 72.208 habitantes e 91.486 habitantes respectivamente, encontrando uma geração per capita de 0,6 Kg.hab-1.dia ${ }^{-1}$ (KONRAD, CASARIL E SCHMITZ ,2010) e 0,66 Kg.hab-1.dia-1 (SCHNEIDER et al., 2002) .

Observaram-se diferenças percentuais significativas entre os municípios, os quais apresentaram grau de dispersão, em relação à média per capita dos resíduos gerados, de 35,6\% $\left( \pm 0,156 \mathrm{Kg} \cdot \mathrm{hab}^{-1} \cdot \mathrm{dia}^{-1}\right)$. Esse fator, segundo Oliveira et. al. (2004), pode estar associado ao poder aquisitivo das populações atendidas e consequentemente ao Produto Interno Bruto (PIB) dos municípios envolvidos pelo estudo. Campos (2012) afirma ainda, que valores menores de geração podem associar-se a regiões mais carentes, enquanto que os valores maiores, às regiões de maior poder econômico.

Ao que se relaciona a caracterização qualitativa dos resíduos, a Figura 1 apresenta a avaliação da composição gravimétrica (porcentagem em relação à massa) dos resíduos destinados a central de triagem, compostagem e disposição final.

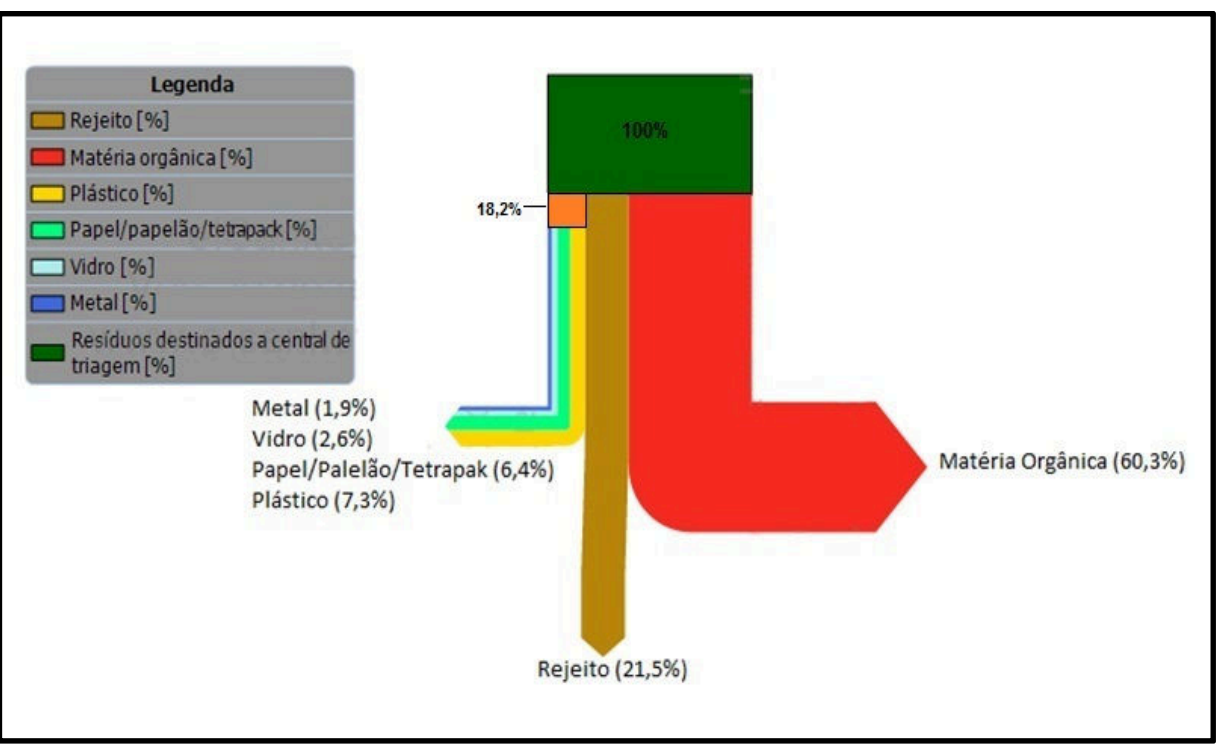

Figura 1: Composição gravimétrica dos resíduos sólidos domésticos destinados a central de triagem, compostagem e disposição final. 
Observando a Figura 1, verifica-se que a maior parte dos resíduos são orgânicos $(60,3 \%$ com relação à massa total de resíduos coletados), estes resíduos são os responsáveis pela proliferação de vetores e geração de percolado nos aterros sanitários, quando não são devidamente tratados. O percentual de material orgânico assemelha-se ao constatado por outros estudos de caracterização gravimétrica, que comprovaram que a maior parcela dos resíduos sólidos domésticos corresponde à fração orgânica (AVELAR, 2006; OLIVEIRA, 2007; FRANCO, 2012; COSTA, 2012), podendo este percentual estar associado aos hábitos alimentares da região.

No que diz respeito ao material considerado rejeito, verificou-se o percentual de participação de $21,5 \%$ em massa, o qual foi destinado para o aterro sanitário localizado na central em estudo. Dentre os rejeitos estão materiais como as fraldas e absorventes e ainda tecidos, borracha e outros materiais não reaproveitáveis. Além disso, somam-se aos rejeitos materiais com potencial para reciclagem que não foram devidamente triados e outros materiais que perderam suas características por estarem sujos ou contaminados.

Os estudos de Avelar (2006), Oliveira (2007), Franco (2012) e Costa (2012), encontraram percentuais variando entre $10 \%$ e $20 \%$ para os rejeitos, demostrando que ainda existe uma parcela dos resíduos domésticos que poderia ser reaproveitada. Salienta-se, no entanto, que não há um processo de separação de resíduos no qual se obtenha um reaproveitamento de $100 \%$ dos materiais, a fração de rejeitos sempre estará presente.

Os materiais recicláveis levantados pelo estudo corresponderam a 18,2\% em relação à massa total dos resíduos triados, são estes os que possuem valor comercial e são encaminhados para venda. O material com maior participação entre os recicláveis é o plástico, que corresponde a $7,2 \%$ em peso dos resíduos, seguido pelo papel/papelão/tetrapack, que apresentou o percentual de $6,4 \%$, estes materiais são os principais constituintes das embalagens em geral, e este é o provável motivo para que apresentem estes percentuais. Cabe ressaltar ainda que, se tratando os municípios de estudo de locais sem coleta seletiva, o percentual encontrado para materiais recicláveis é significativo.

Avaliando estudos de outros municípios, realizados por Avelar (2006), Oliveira (2007), Franco (2012) e Costa (2012), constataram-se percentuais para materiais recicláveis entre $14 \%$ e $33 \%$. Desse modo, demonstra-se que o percentual encontrado para esse material nesse estudo, está de acordo com a realidade de outros municípios, porém confrontando com a quantidade de rejeitos que ainda existe nos resíduos caracterizados, percebe-se que as melhorias nas práticas de descarte e a coleta seletiva, poderiam elevar os percentuais de materiais com potencial para reciclagem.

Ainda tratando-se do material plástico, constatou-se que do total de resíduos constituídos por esse material (7,2\% do total de resíduos triados), 47,7\% eram PEBD, polímero amplamente utilizado na confecção de sacolas plásticas, $23,8 \%$ eram plásticos do tipo PET a partir do qual se fabricam garrafas plásticas de bebidas principalmente e 21,6\% correspondiam ao PEAD, material presente nos frascos e embalagens de alimentos, cosméticos e produtos de limpeza. Verifica-se 
que a maior parte do polímero presente na parcela dos recicláveis se concentra no PEBD, constituinte das sacolas plásticas, que geralmente são geradas nas compras do dia a dia. A prática do seu uso poderia ser facilmente substituída por sacolas reutilizáveis, como as de pano.

\section{CONCLUSÕES}

Com relação ao total de resíduos sólidos domésticos coletados, aproximadamente $80 \%$ em massa são passíveis de reaproveitamento, seja por reciclagem $(18,2 \%)$ ou compostagem $(60,3 \%)$, enquanto $21,5 \%$ foram considerados rejeito. Conclui-se que a prática da coleta seletiva ainda poderia aumentar o percentual de materiais recicláveis, contribuindo para um maior reaproveitamento destes e aumentando a vida útil da célula do aterro sanitário.

Através desse estudo pôde-se entender como foram gerenciados os resíduos coletados, após sua chegada a uma central de triagem, compostagem e disposição final. Além do mais, foi possível traçar um perfil da composição gravimétrica dos resíduos de um grupo de pequenos municípios contribuindo assim, para estudos no mesmo sentido que venham a ser realizados em outros locais com características semelhantes.

\section{REFERÊNCIAS}

AVELAR, S. A.. Avaliação do sistema de gerenciamento de resíduos sólidos urbanos do município de Coronel Fabriciano, Minas Gerais. Dissertação (Mestrado) - Centro Universitário de Caratinga, Caratinga, 2006.

BRAGA, J. O. N.; COSTA, L. A.; GUIMARRÃES, L. A.; RODRIGUES, J. C. T.. O uso do geoprocessamento no diagnóstico dos roteiros de coleta de lixo da cidade de Manaus. Revista Engenharia Sanitária e Ambiental. Rio de Janeiro, v.13, n.4, p.387-394, 2008.

BRASIL. Lei no 12.305, de 2 de agosto de 2010. Institui a Política Nacional de Resíduos Sólidos, altera a Lei n. 9.605, de 12 de fevereiro de 1998 e dá outras providências. Brasília, 03 ago. 2010.

BIDONE, F. R. A.; POVINELLI, J.. Conceitos básicos de resíduos sólidos. São Carlos: EESC-USP, 1999.

CALDERAN, T. B.. Consórcio Público Intermunicipal de Gerenciamento de Resíduos Sólidos Domésticos: um estudo de caso. Dissertação (Mestrado em Ambiente e Desenvolvimento: espaço, ambiente e sociedade) - Centro Universitário UNIVATES, Lajeado, 2013.

CAMPOS, H. K. T.. Renda e evolução da geração per capita de resíduos sólidos no Brasil. Revista Engenharia Sanitária e Ambiental, v.17, n.2, p.171-180, 2012.

CASTILHOS JÚNIOR, A. B.. Resíduos sólidos urbanos: aterro sustentável para municípios de pequeno porte (Coord.). Rio de Janeiro: Projeto PROSAB, ABES, 2003.

COSTA, L. E. B.; COSTA, S. K.; REGO, N. A. C.; SILVA JUNIOR, M. F.. Gravimétrica dos resíduos sólidos urbanos domiciliares e perfil socioeconômico no município de Salinas, Minas Gerais. Revista Ibero-

Americana de Ciências Ambientais, Aquidabã, v.3, n.2, p.73-90, 2012.

FRANCO, C. S.. Caracterização gravimétrica dos resíduos sólidos domiciliares e percepção dos hábitos de descarte no sul de Minas Gerais. Dissertação (Mestrado em Recursos Hídricos em Sistemas Agrícolas) - Universidade Federal de Lavras, Lavras, 2012. 
FUZARO, J. A.; RIBEIRO, L. T.. Coleta seletiva para prefeituras. 3 ed. São Paulo: Secretaria do Meio Ambiente, 2003.

IBGE. Instituto Brasileiro de Geografia e Estatística. Pesquisa Nacional de Saneamento Básico 2008. Rio de Janeiro: IBGE, 2010.

JACOBI, P.R.. Gestão compartilhada dos resíduos sólidos no Brasil - Inovação com inclusão social. São Paulo: Annablume, 2006.

KONRAD, O.. Modellversuch Estrela zur Sammlung, Trennung und Behandlung von Hausmüll in Brasilien. Tese (Doutorado) - Montan universität Leoben, Leoben-Austria, 2002.

KONRAD, O.; CALDERAN, T. B.. A preservação ambiental na visão da política nacional dos resíduos sólidos. Rio Grande: Âmbito Jurídico, 2011.

KONRAD, O.; CASARIL, C. E.; SCHMITZ, M.. Estudo dos resíduos sólidos domésticos de Lajeado/RS pela caracterização gravimétrica. Destaques Acadêmicos, n.4, p.57-62, 2010.

LEME, S. M.; JOIA, P. R.. Caracterização física dos resíduos sólidos urbanos domiciliares em Aquidauana, MS. Geografia, v.15, n.1, p.35-49, 2006.

LIMA, J. D.. Gestão de resíduos sólidos urbanos no Brasil. João Pessoa: ABES, 2001.

OLIVEIRA, S. A.; LEITE. V. D.; PRASAD, S.; RIBEIRO, M. D.. Estudo da produção per capita de resíduos sólidos domiciliares da cidade de Campina Grande-PB. Revista Saúde e Ambiente, v.5, n.2, p.37-44, 2004.

OLIVEIRA, N. M. S.; MORAIS, C. R. S.; SILVA, H. C.; CAVALCANTI, M. S. L.; LUCENA, L. F. L.. Estudo Gravimétrico de Resíduos Vítreos Domésticos do Lixão de Campina Grande. In: CONGRESSO BRASILEIRO DE CERÂMICA, 51. Anais. Salvador: 2007.

OLIVEIRA, S.. Gestão de resíduos sólidos urbanos (RSU) na Microrregião Serra de Botucatu/SP. Revista Limpeza Pública da ABLP, São Paulo, n.47, p.10-21, 1998.

PESSIN, N.; CONTO, S. M.; TELH, M.; CADORE, J.; ROVATTI, D.; BOFF, R. E.. Composição gravimétrica de resíduos sólidos urbanos: estudo de caso - município de Canela - RS. In: CONGRESO INTERAMERICANO DE INGENIERIIA SANITARIA Y AMBIENTAL, 30. Anais. Punta del Este: 2006.

SCHNEIDER, V. E.; PANAROTTO, C. T.; PERESIN, D.; REGINATO, P.A. R.; MARCON, F.. Evolução da geração de resíduos sólidos do município de Bento Gonçalves, R.S- No período de 1993 a 2001. In: CONGRESO INTERAMERICANO DE INGENÍERIA AMBIENTAL, 28. Anais. Cancun: 2002

TABALIPA, N. L.; FIORI, A. P.. Caracterização e Classificação dos Resíduos Sólidos Urbanos do Município de Pato Branco, PR. Revista Brasileira de Ciências Ambientais, n.4, p.23-33, 2006.

ZANIN, M.; MANCINI, S. D.. Resíduos Plásticos e Reciclagem: aspectos gerais e tecnologia. São Carlos: EdFSCar, 2004. 